1 Tribunal de Justiça do Estado do Rio de Janeiro (TJRJ) - Rio de Janeiro (RJ), Brasil.

taniapaim@tjri.jus.br

2 Tribunal de Justiça do Estado do Rio de Janeiro (TJRJ), Escola da Magistratura do Estado do Rio de Janeiro (Emerj) Rio de Janeiro (RJ), Brasil.

3 Fundação Oswaldo Cruz (Fiocruz), Escola Nacional de Saúde Pública Sergio Arouca (Ensp), Departamento de Direitos Humanos, Saúde e Diversidade Cultural (DIHS) - Rio de Janeiro (RJ), Brasil.

\section{Acesso das pessoas com deficiência mental aos direitos e garantias previstos na Lei Brasileira de Inclusão por meio do Sistema Único de Assistência Social}

\author{
Access of persons with mental disabilities to the rights and guarantees \\ provided for in the Brazilian Inclusion Law through the Unified Social \\ Assistance System
}

Tania Paim Caldas de Abreu1, Maria Aglaé Tedesco Vilardo ${ }^{2}$, Aldo Pacheco Ferreira ${ }^{\mathbf{3}}$

\begin{abstract}
RESUMO Desde 2005, está previsto na Constituição o Sistema Único de Assistência Social (Suas), descentralizado e participativo, que tem por função a gestão da assistência social no campo da proteção social brasileira. Em 2015, foi promulgada a Lei Brasileira de Inclusão da Pessoa com Deficiência destinada a assegurar e a promover o exercício dos direitos e liberdades fundamentais por pessoa com deficiência, visando a sua inclusão social e a sua cidadania, em cumprimento à Convenção Internacional sobre os Direitos das Pessoas com Deficiência. Assim como a saúde e a previdência, a assistência social é um direito social do cidadão e dever do Estado; suas ações fazem parte da Política de Seguridade Social não contributiva. Buscou-se, portanto, investigar o acesso e o recebimento de informações, das pessoas com deficiência mental, aos direitos e garantias previsto no Suas, em Campo Grande, bairro da Zona Oeste do município do Rio de Janeiro, por meio da pesquisa documental e de campo, com entrevista individual semiestruturada. Constatou-se falta de conhecimento, de informação adequada, de educação continuada dos profissionais, de estrutura física. Conclui-se que, não obstante as normas avançadas, protetivas de direitos humanos, o Estado ainda não reduziu, efetivamente, as desigualdades sociais, especialmente para as pessoas com deficiência mental.
\end{abstract}

PALAVRAS-CHAVE Serviço social. Deficiência intelectual. Política pública. Direitos humanos. Saúde pública.

ABSTRACT Since 2005, the decentralized and participatory Unified Social Assistance System (Usas) is provided for in the Constitution, whose function is the management of Social Assistance in the field of Brazilian social protection. In 2015, the Brazilian Law on the Inclusion of Persons with Disabilities was enacted to ensure and promote the exercise of fundamental rights and freedoms by persons with disabilities, with a view to their social inclusion and citizenship, in compliance with the International Convention on Human Rights of People with Disabilities. Like health and social security, social assistance is a social right of the citizen and a duty of the state; its actions are part of the non-contributory Social Security Policy. Therefore, we sought to investigate the access and reception of information, by people with mental disabilities, to the rights and guarantees provided by Usas, in Campo Grande, neighborhood of the West side of Rio de Janeiro, through documentary and field research, with semi-structured individual interview. There was a lack of knowledge, of adequate information, of continuing education of professionals, of physical structure. It is concluded that, however advanced the protective human rights norms, the State has not yet effectively reduced social inequalities, especially for people with mental disabilities.

KEYWORDS Social work. Intellectual disability. Public policy. Human rights. Public health. 


\section{Introdução}

O estudo analisa o acesso das pessoas com deficiência mental aos direitos e garantias previstos na Convenção Internacional de Direitos da Pessoas com Deficiência ${ }^{1}$ a partir da entrada em vigor da Lei Brasileira de Inclusão da Pessoa com Deficiência - LBI (Estatuto da Pessoa com Deficiência) ${ }^{2}$, em 2016, por meio do Sistema Único da Assistência Social (Suas) ${ }^{3}$. No que diz respeito à contribuição, à construção do conhecimento, tem-se, na proposta de pesquisa, uma base reflexiva que contribui para o serviço social relacionado com as pessoas com deficiência mental, no intuito de ressaltar as potenciais inconsistências que ocorrem na interface entre as múltiplas expressões da questão social e as estratégias de gestão e organização da sociedade, tendo-se como meta a garantia dos direitos sociais e o efetivo exercício da cidadania, delineados no Suas ${ }^{3}$.

Embora, desde 2009, a convenção tenha status de norma constitucional, somente passou a ser discutida e conhecida a partir de sua regulamentação por lei ordinária e das alterações que introduziu no Código Civil e Código de Processo Civil em 2015.

As pessoas com deficiência são colocadas como protagonistas de suas histórias de vida, em um projeto universal de inclusão sob o lema 'Nada sobre Nós, sem Nós' que expressa a obstinação dessas pessoas de serem ouvidas, pois ninguém melhor do que a pessoa com deficiência para apontar e reclamar seus direitos; apontar e reclamar a discriminação, a exclusão e a opressão sofrida, impostas por um a sociedade deficiente.

Nusbaumm $^{4}$, na defesa do enfoque das capacidades, sustenta a existência de uma dimensão moral e social das partes no pacto social. Entende a autora que os seres humanos cooperam motivados por um amplo campo de ensejos, entre eles, o amor pela própria justiça e, em especial, por uma compaixão moralizadora por aqueles que possuem menos do que precisam para levar vidas decentes e dignas. Nas palavras da autora:
Da minha parte, diria que a mudança que percebemos nos anos recentes em direção a uma inclusão social maior de pessoas com impedimentos representa uma clara evidência de que a decência faz que os seres humanos busquem a justiça em si mesma, e tão frequentemente de modo que produza uma grande diferença política4(194).

É desse espírito que nascem as declarações de direitos humanos abraçadas pelos povos paulatinamente. Ao lado de um sistema geral de direitos, como a Declaração Universal de Direitos Humanos ${ }^{5}$, são organizados sistemas especiais, como a Declaração dos Direitos das Pessoas com Deficiência.

A Convenção sobre os direitos das pessoas com deficiência, também conhecida como Convenção de Nova York ${ }^{\mathbf{1}}$, e a LBI ${ }^{\mathbf{2}}$ têm como destinatários toda a gama de pessoas com deficiência, categorizadas em deficiência física, intelectual, mental e sensorial.

As possibilidades de acesso aos serviços públicos, à saúde e à educação são prejudicadas pela falta de recursos, especialmente o financeiro, além da falta de informação em função da condição socioeconômica. A meta para essas pessoas limita-se a assegurar sua própria sobrevivência e, se houver, da família, na qual um dos membros será sacrificado para os cuidados com pessoa com deficiência para exercer a função de cuidador; que, na esmagadora maioria das vezes, é uma mulher.

A seguridade social compreende um conjunto integrado de ações de iniciativa dos Poderes Públicos e da sociedade, destinadas a assegurar os direitos relativos à saúde, à previdência e à assistência social, conforme art. 194 da Constituição da República de 19886:

Art. 194. A seguridade social compreende um conjunto integrado de ações de iniciativa dos Poderes Públicos e da sociedade, destinadas a assegurar os direitos relativos à saúde, à previdência e à assistência social. 
A assistência social na Constituição Cidadã vem pela primeira vez estabelecida como direito social: de ser assistido e a vencer, com apoio de políticas públicas, o estado de vulnerabilidade social.

A pessoa com deficiência tem direito constitucional, entre muitos outros, à assistência social, visando sua habilitação e reabilitação e sua integração à vida comunitária.

A assistência social foi organizada, nos moldes do Sistema Único de Saúde 7 (SUS), como sistema de gestão descentralizado, integrado por todos os entes federativos, pelos respectivos conselhos de assistência social e pelas entidades e organizações de assistência social na forma prevista na Lei Orgânica da Assistência Social (Loas) ${ }^{\mathbf{8}}$, constituindo o Suas ${ }^{3}$.

Por conseguinte, o nicho social foco desta pesquisa é aquele destinatário das políticas de assistência social. São pessoas cuja condição socioeconômica, educação e saúde são fatores de exclusão, discriminação, violação de direitos, e ainda com fator de agravamento das condições de vida, a deficiência mental, afastando-as dos padrões de dignidade que devem usufruir todos os seres humanos. $\mathrm{O}$ desconhecimento do direito que são titulares promove maior desamparo aos vulnerados por doenças mentais.

\section{A deficiência mental na Convenção Internacional de Direitos das Pessoas com Deficiência}

\footnotetext{
A Convenção Internacional de Direitos da Pessoas com Deficiência ${ }^{1}$ e a LBI ${ }^{2}$, utilizam o mesmo conceito de pessoa com deficiência: a pessoa com deficiência é aquela que tem impedimento de longo prazo de natureza física, mental, intelectual ou sensorial, o qual, em interação com uma ou mais barreiras, pode obstruir sua participação plena e efetiva na sociedade em igualdade de condições com as demais pessoas.
}

Duas questões se apresentam. Qual a distinção entre deficiência intelectual e deficiência mental? Por que a Convenção Internacional de Direitos das Pessoas com Deficiência ${ }^{1}$ e a LBI ${ }^{2}$ se referiram a ambas no rol das deficiências como categorias de naturezas diversas?

Lopes $^{9}$ menciona que a sociedade civil pleiteou a inclusão do termo psicossocial no conceito de pessoa com deficiência, o que poderia implicar dificuldade na ratificação da Convenção, em razão das diferentes formas dos países tratarem a questão da deficiência e da saúde mental, inclusive o Brasil. Diante desse impasse, relata a autora, optou-se por manter o termo 'mental' e a inclusão da expressão 'intelectual', permitindo uma margem para os Estados signatários tratarem o conceito internamente, e decidir se as pessoas com transtornos mentais estão contempladas pela Convenção.

No Brasil, essa questão ainda não foi regulamentada, estando as categorias de deficiência definidas pelo Decreto $n^{0} 5.290 / 2004^{10}$ que, ainda, está em vigor. Enquanto não ocorrer uma adequação do conceito de deficiência em norma regulamentar em harmonia aos novos paradigmas introduzidos pela Convenção Internacional de Direitos das Pessoas com Deficiência', inclusive quanto à distinção indiciada por ela entre deficiência mental e intelectual, continuam válidas, para fins de definição de deficiência, as categorias estabelecidas no Decreto, contanto que não importem em restrição de direitos. A LBI$^{2}$ não resolveu a questão.

Diante dessa imprecisão, alguns interpretam o termo 'intelectual' como atualização do termo 'mental' em consonância com a Declaração de Montreal1". Outros defendem que as pessoas com transtornos psicossociais ou usuários da saúde mental foram contemplados na definição nacional de deficiência ${ }^{12}$.

Está em andamento no Congresso o Projeto de Lei $\mathrm{n}^{0} 5.907 / 2016$ que altera a Lei $\mathrm{n}^{0}$ 10.216/2001'3 , conhecida como a Lei da Reforma Psiquiátrica, que dispõe sobre a proteção e os direitos das pessoas com transtorno mental e redireciona o modelo assistencial em saúde mental. O Projeto de Lei apresentado à Câmara 
dos Deputados acrescenta dispositivos à referida lei, entre eles, o parágrafo único ao art. $1^{\circ}$ pelo qual estabelece que a pessoa com transtorno mental é considerada pessoa com deficiência, para todos os efeitos legais. O projeto recebeu parecer favorável da Comissão de Seguridade Social e Família em 14 de setembro de 2017.

Mencionam Feminella e Lopes ${ }^{\mathbf{1 2}}$ que a Convenção foi fruto do esforço comum de pessoas do campo da saúde mental e de pessoas do campo das deficiências, pretendendo o reconhecimento que a sequela do transtorno mental constituísse mais uma deficiência, entre as deficiências física, intelectual e sensorial.

O termo deficiência psicossocial ${ }^{\mathbf{1 4}}$ refere-se à classificação de um problema nas funções mentais de um indivíduo, que podem ser uma ou mais limitações das capacidades de consciência, aprendizado, interação social, temperamento, energia e impulso, estabelecimento de vínculos, personalidade, atenção, memória, concentração, linguagem, percepção, conforme a classificação das funções mentais pela Classificação Internacional de Funcionalidade, Incapacidade e Saúde (CIF) ${ }^{\mathbf{1 5}}$. Ressaltam os autores mencionados que o indivíduo com transtorno mental, de caráter crônico e persistente, enfrenta barreiras que limitam sua participação plena em situação de igualdade na sociedade, portanto, considera-se esse indivíduo com deficiência psicossocial albergado pela Convenção Internacional de Direitos da Pessoas com Deficiência ${ }^{1}$ e pela $\mathrm{LBI}^{2}$. São pessoas com agravos funcionais e intelectuais que resultam no comprometimento na sua capacidade de desempenho e participação em atividades.

Para Costa $^{16}$, a inclusão das pessoas com transtorno mental no rol das pessoas com deficiência constitui uma questão de justiça, visto que são pessoas que experimentam significativos impedimentos de natureza psicossocial e são fortemente discriminadas.

Essa questão deve ser analisada com cautela, pois doença não importa necessariamente em deficiência, embora a pessoa com transtorno mental, como acima mencionado, possa sofrer algum tipo de limitação ou impedimento. Encontramos na CIF ${ }^{15}$ o exemplo do indivíduo com problemas de desempenho sem deficiências ou limitações de capacidade, sendo dado o exemplo de ex-doente curado de doença mental, que enfrenta estigmas ou discriminação nas relações interpessoais ou no trabalho. Portanto, uma generalização do conceito para incluir indiscriminadamente a pessoa com transtorno mental no rol das pessoas com deficiência para o fim de abrangê-las pela $\mathrm{LBI}^{2}$ parece precipitado ${ }^{15}$.

Os transtornos mentais graves podem influenciar na funcionalidade psíquica e social, caracterizando a deficiência psicossocial, caso persistam as limitações funcionais após tratamento médico.

No Brasil, o conceito de deficiência para fins de recebimento do Benefício de Prestação Continuada (BPC) está previsto no Anexo I do Decreto $n^{0} 6.214^{17}$, utilizando para avaliação da deficiência e grau de incapacidade os parâmetros definidos da CIF ${ }^{\mathbf{1 4}}$, Portaria Conjunta MDS/INSS no $2 / 2015^{18}$. A CIF ${ }^{15}$ é uma das classificações desenvolvidas pela Organização Mundial da Saúde (OMS), ao lado da Classificação Internacional de Doenças, Décima Revisão (CID-10).

A funcionalidade é um termo que engloba todas as funções do corpo, atividades e participação; de maneira similar, deficiência é um termo que inclui impedimentos, limitação da atividade ou restrição na participação ${ }^{15}$.

Nas classificações internacionais da OMS, os estados de saúde (doenças, perturbações, lesões etc.) são classificados principalmente na CID-10 que fornece uma estrutura de base etiológica. A funcionalidade e a incapacidade associadas aos estados de saúde são classificados na CIF ${ }^{15}$. Portanto, a CID-10 e a CIF'15 são complementares. As deficiências, como consta da CIF ${ }^{15}$, correspondem a um desvio em relação a um padrão aceito como estado biomédico normal do corpo e das suas funções. A definição dos seus componentes é feita essencialmente por pessoas com competência para avaliar a funcionalidade física e mental, de acordo com esses padrões. 


\section{Lei Brasileira de Inclusão da Pessoa com Deficiência}

Pela Convenção Internacional de Direitos da Pessoas com Deficiência ${ }^{1}$, o Brasil, no art. $4^{\circ}$, comprometeu-se a adotar todas as medidas legislativas, administrativas e de qualquer natureza necessárias para a realização dos direitos e garantias nela reconhecidos.

Com efeito, é vocacionada a assegurar e a promover, em condições de igualdade, o exercício dos direitos e das liberdades fundamentais pela pessoa com deficiência, visando à sua inclusão social e cidadania. Assim, pretende inaugurar uma nova fase no tratamento da pessoa com deficiência por meio da eliminação das barreiras existentes, ambientais e sociais, incorporação de instrumentos para habilitação e reabilitação e a criação de mecanismos para possibilitar a plena inclusão da pessoa com deficiência. Representa uma revolução no ordenamento jurídico, excluiu qualquer referência à incapacidade em razão da deficiência, trouxe alterações profundas no Código Civil e no Código de Processo Civil, entre eles, a eliminação do termo 'interdição’, que produz e reproduz preconceito, discriminação e isolamento da pessoa com deficiência, nas palavras de Rosenvald ${ }^{19}$ :

Remete a uma sanção civil de natureza punitiva a quem não praticou qualquer ato ilícito. Observa o mencionado autor que mesmo tendo CPC/2015 se servido do termo interdição em diversas passagens (arts.747 a 757), a Lei 13.105/2015 deve deferência à CDPD, em face de sua superioridade normativa19(736).

Tendo como base a Convenção Internacional de Direitos da Pessoas com Deficiência ${ }^{1}$, a $\mathrm{LBI}^{2}$ define a deficiência não mais como uma condição estática e biológica, mas, sim, como resultado da interação das barreiras impostas pelo meio e pela sociedade com as limitações de natureza física, mental, intelectual e sensorial do indivíduo. As barreiras são obstáculos que podem se apresentar de diversas formas, e devem ser removidos ou adaptados razoavelmente de forma a permitir que a pessoa com deficiência possa desfrutar de seus direitos em igualdade de condições com as demais pessoas (art. $3^{\circ}$ da LBI) ${ }^{2}$.

A Convenção Internacional de Direitos das Pessoas com Deficiêncial e a $\mathrm{LBI}^{2}$ rompendo com as âncoras epistemológicas da anatomopatologia transferem o foco para o ser humano em todas as suas possibilidades. Não trata do homem deficiente, mas do homem com deficiência que, em razão dela, demanda ações afirmativas do Estado para sua realização e inclusão plena na vida.

Não se trata de negar as limitações de natureza física, mental ou intelectual, mas, reconhecendo-as, erguer estruturas culturais, sociais, cientificas e jurídicas para superação e inclusão do ser humano com deficiência.

Como lembrado por Feminella e Lopes ${ }^{12}$, a $\mathrm{LBI}^{2}$ organiza, em uma única lei nacional, como um verdadeiro marco regulatório para as pessoas com deficiência, direitos e deveres que estavam dispersos em outras leis, decretos e portarias, regulamentando limites e condições e atribuindo responsabilidades para cada ator na consolidação da assistência social na $\mathrm{LBI}^{2}$.

\section{Organização da assistência social no município do Rio de Janeiro - Bairro de Campo Grande}

No município do Rio de Janeiro, atualmente, dentro da estrutura organizacional do Poder Executivo, temos a Secretaria de Assistência Social e Direitos Humanos composta de diversas subsecretarias, entre elas, a Subsecretaria de Proteção Social Básica e Especial, integrada por dez Coordenadorias de Assistência Social. Focamos a análise na região de Campo Grande, a qual constitui a $9^{\circ}$ Coordenadoria de Assistência Social, integrada por três Centros de Referência de Assistência Social (Cras), um Centro de Referência Especializado de Assistência Social (Creas) e o Centro de Alta Complexidade. Campo Grande é o bairro mais extenso e o mais populoso do município do Rio 
de Janeiro com uma grande população vivendo em comunidades de baixa renda.

O sucesso de qualquer empreendimento está diretamente relacionado com o correto dimensionamento da equipe e da qualidade dos recursos humanos empregados para consecução de sua finalidade. No caso da assistência social, faz-se necessário localizar territorialmente onde se encontram e quais são os principais focos de vulnerabilidade socioassistencial e sua dimensão, estabelecendo uma relação pessoa-território para o adequado planejamento da gestão e da oferta da proteção social ${ }^{19}$.

As metrópoles que possuem gestão plena das ações da assistência social, como o município do Rio de Janeiro, devem estruturar os Cras, em áreas de maior vulnerabilidade social, devendo contar, no mínimo, com 8 Cras, cada um com capacidade para atendimento de até 5 mil famílias referenciadas conforme a Política Nacional de Assistência Social $(\mathrm{PNAS})^{\mathbf{2 0}}$ e a Norma Operacional Básica do Suas (NOB-Suas) ${ }^{21}$. A NOB-Suas 21(21) define família referenciada como

aquela que vive em áreas caracterizadas como de vulnerabilidade, definidas a partir de indicadores estabelecidos por órgão federal, pactuados e deliberados.

Conhecido o número de famílias referenciadas, são constituídas as equipes de referência formadas por servidores efetivos responsáveis pela organização e pela oferta de serviços, programas, projetos e benefícios de proteção social básica e especial, levando-se em consideração o número de famílias e indivíduos referenciados, o tipo de atendimento e as aquisições que devem ser garantidas aos usuários $^{\mathbf{2 1}}$. Ferreira ${ }^{22}$ esclarece que:

[...] são referências de proteção social para as famílias e indivíduos, que têm nas equipes a certeza de que encontrarão respostas qualificadas para suas necessidades. [...] Uma referência, portanto, construída a partir de conhecimentos técnicos específicos e de uma postura ética que, ao acolher as necessidades sociais dos cidadãos como direito, acenam em direção a horizontes mais acolhedores, compartilhados e de maior autonomia22(26).

De acordo com o nível de proteção (básica ou especial, de média ou alta complexidade) e com o tipo de serviço socioassistencial, cada grupo de usuário fica sob a responsabilidade de uma equipe de referência que se torna referência para esses usuários.

Em síntese, as equipes de referência do Suas devem produzir para o cidadão a certeza de que ele encontrará acolhida, convívio e meios para o desenvolvimento de sua autonomia ${ }^{22}$.

Para eficiente distribuição das Unidades de referência, planejamento estratégico, é preciso conhecer a dimensão do desafio a ser enfrentado no território, a realidade social do território, onde está instalado o centro de referência para um efetivo atendimento da comunidade dentro de um planejamento estratégico.

Essa valiosa informação deve ser obtida por meio da vigilância socioassistencial prevista no art. $2^{\circ}$, II c.c. art. $6^{\circ} \mathrm{A}$ da Loas $^{8}$ (art. 87 e seguintes), constituindo instrumento de proteção social na identificação e na prevenção das situações de risco e vulnerabilidade social.

A equipe que atua nos Cras está totalmente absorvida na demanda que bate à sua porta, chamada demanda espontânea, sendo que a esmagadora maioria vai em busca de benefícios garantidores de renda mínima, no caso da pessoa com deficiência, o BPC. A centralização nesse benefício revela o alto nível de empobrecimento das pessoas e o desconhecimento de toda gama direitos de que são titulares.

$\mathrm{O}$ art. $6^{\circ}$, I e parágrafo único da Loas $^{8} \mathrm{e}$ PNAS $^{20}$ estabelecem caber ao Cras a vigilância socioassistencial, devendo manter ativo

[...] um serviço de vigilância da exclusão social na produção, sistematização e divulgação de indicadores da área de abrangência do Cras [...], [contudo] [...] o cadastro único absorve o pessoa| ${ }^{20(35)}$. 
Sobre essa questão, tivemos a oportunidade de verificar nos depoimentos a inexistência desse trabalho de forma sistemática no território pesquisado:

A vigilância socioassistencial deveria fazer uma busca no território, o que não ocorre como deveria porque estão absorvidos pela demanda espontânea. Além disso, a estrutura de pessoal não permite alcançar a integralidade do território. (Ecras).

Forçoso concluir que são desconhecidas as necessidades das pessoas e famílias localizadas em Campo Grande, entre elas, as pessoas com deficiência mental para as quais nenhuma estrutura específica foi implantada nos centros de referência de proteção social básica e especial (Cras e Creas), tampouco são ofertados por essas unidades serviço ou programas além do BPC.

A incapacidade e a inexistência de oferta de serviços, programas e projetos de proteção social no território revelaram-se evidentes nos seguintes relatos: “[...] a principal demanda que chega ao Cras é cadastro único (99\%), [...] ressalta-se, o Cras apenas realiza cadastro único" (Ecras).

A Norma Operacional Básica de Recursos Humanos (NOB-RH/Suas) ${ }^{23}$ prevê a composição da equipe de referência dos Cras para a prestação de serviços e execução das ações no âmbito da proteção social básica, sendo que, nos municípios de grande porte e metrópoles, a cada 5 mil famílias referenciadas, deverá haver 4 técnicos de nível superior, sendo 2 profissionais assistentes sociais, 1 psicólogo e 1 profissional que compõem o Suas, e 4 técnicos de nível médio.

Em Campo Grande, temos três Cras, cada um com responsabilidade sobre determinada área do bairro. Em todos eles, observou-se a equipe mínima prevista; estrutura de pessoal que, como se pode perceber, é absorvida pelo cadastro único, sua alimentação e atualização.

Há, ainda, em Campo Grande, um Creas que é uma unidade pública que se constitui como polo de referência, coordenador e articulador da proteção social especial de média complexidade. No caso do Rio de Janeiro, município que possui gestão plena, cada Creas deve ter capacidade de atendimento de 80 indivíduos; seu quadro de pessoal deverá contar com 2 assistentes sociais, 2 psicólogos, 1 advogado, 4 profissionais de nível superior ou médio (abordagem dos usuários) e 2 auxiliares administrativos.

Observou-se, assim como nos Cras, que o único Creas localizado em Campo Grande conta com a estrutura de pessoal mínima prevista na NOB-RH/Suas ${ }^{23}$.

À idêntica constatação na pesquisa de campo chegou a equipe de autores da obra conjunta 'O Sistema Único de Assistência Social no Brasil - uma realidade em movimento'24(15), quanto

[...] a limitada capacidade de atendimento dos Cras e Creas as demandas assistenciais que extrapolem a simples distribuição de benefícios, particularmente o do Programa Bolsa Família - que representa a incumbência central dessas unidades.

Além dos Cras e Creas, também funciona em Campo Grande a proteção social de alta complexidade responsável pelo serviço de acolhimento institucional voltado para pessoa com vínculos familiares rompidos ou fragilizados. Os serviços envolvem, por exemplo, o abrigamento de pessoas em situação de rua e família acolhedora para jovens e crianças.

Um detalhe que chama atenção no quadro de pessoal dos profissionais que atuam nos Cras/Creas é a predominância de mulheres, tanto coordenadoras quanto a maioria dos funcionários, em que somente encontramos um homem como assistente social. Não são mais 'as moças de caridade', mencionadas por Santos e Brun ${ }^{24}$, associadas à prática assistencialista do cuidar caritativo, solidário, mas profissionais responsáveis pela execução de um direito social fundamental.

Essa predominância feminina também chamou atenção na pesquisa desenvolvida por Couto et al. ${ }^{25}$, anotando que essa característica 
parece influenciar tanto no arranjo decorativo do ambiente quanto nas atividades desenvolvidas que se revelam mais atrativas para o público feminino. Registram que é:

[...] ainda frágil a compreensão dos usuários quanto a institucionalidade pública do trabalho e da unidade, prevalecendo ainda entendimentos que as conquistas efetivadas ocorreram pela 'bondade' dos profissionais, revelando um dos tracos persistentes da assistência social que é a 'pessoalização' das atenções e conquistas [...] 25(2712).

Foi abordado aos participantes da entrevista no Cras sobre a pessoa que exerce a função de cuidador da pessoa com deficiência. Revelaram que os cuidadores, em geral, são mulheres; são elas que vão em busca de auxílio. Essas mulheres, em geral, deixaram o mercado de trabalho para se dedicar aos cuidados da pessoa com deficiência, dependendo financeiramente do BPC para sua manutenção. Essa característica marcante desse nicho social, a impossibilidade de exercício de uma atividade produtiva pelo cuidador, além de diminuir a renda do núcleo familiar, já privado de bens e serviços em razão da precária condição socioeconômica, tem a situação agravada com o óbito da pessoa com deficiência. Com isso, o cuidador fica completamente sem condições de prover sua subsistência, antes minimamente mantido pelo BPC da pessoa com deficiência, e encontra imensa dificuldade de recolocação no mercado de trabalho em razão da idade, da falta de capacitação profissional e pela inexistência de uma rede socioassistencial.

\section{Capacitação da equipe, Centro de Re- ferência de Assistência Social (Cras), Campo Grande, município do Rio de Janeiro}

A capacitação dos profissionais é estratégica para a implantação, incorporação e desenvolvimento de novas tecnologias, novos conhecimentos e para consecução eficiente de trabalho técnico profissional.

A Convenção Internacional de Direitos das Pessoas com Deficiência ${ }^{1}$ e a LBI ${ }^{2}$ introduziram novos conceitos sobre a deficiência, introduziram um novo olhar sobre a pessoa com deficiência e determinaram a execução de ações. Trouxeram, inclusive, uma nova forma de se referir a essas pessoas - não mais como portadores de um mal que as coloca em uma situação especial ou de desvantagem, um ser especial vítima de preconceito e estigma que carrega consigo uma deficiência.

A efetivação do compromisso assumido perante a comunidade internacional e o povo brasileiro ao ratificar a Convenção Internacional de Direitos da Pessoas com Deficiência ${ }^{1}$ e aprová-la com força de emenda constitucional impõe um processo de reeducação da sociedade; impõe o refazimento de espaços, tornando-os acessíveis às pessoas com deficiências; impõe o emprego de novas tecnologias, adoção de novos comportamentos; impõe o treinamento adequado de profissionais para que estejam aptos a criar, a viabilizar e a executar novos projetos, permitindo que as pessoas com deficiência desenvolvam toda sua potencialidade enquanto pessoas livres e capazes.

Para os profissionais da assistência social, aos quais cabe a execução de projetos, serviços e programas no âmbito da proteção social tendo como usuários as pessoas com deficiência; o treinamento, a capacitação e o conhecimento da nova legislação são fundamentais para sua plena materialização.

\section{Educação permanente e capacitação, Centro de Referência de Assistência Social (Cras), Campo Grande, muni- cípio do Rio de Janeiro}

$\mathrm{O}$ abandono da arcaica visão assistencialista e o estabelecimento da assistência social como política social reclamam a formação de um corpo técnico qualificado para lidar e analisar as mais variadas situações do cotidiano enfrentadas pelas pessoas com deficiência. 
É salientado na PNAS20 que a produtividade e a qualidade dos serviços oferecidos à sociedade no campo das políticas públicas estão relacionadas com a forma e com as condições como são tratados os recursos humanos. É evidente que uma política de capacitação dos trabalhadores, gestores e conselheiros da área, de forma sistemática e continuada, deve integrar a política de recursos humanos.

Prevê a Loas ${ }^{8}$, art. 30, entre as condições para que os municípios, estados e Distrito Federal recebam repasses dos recursos do Fundo Nacional de Assistência Social, a existência de um Plano de Assistência Social cujas ações de apoio técnico e financeiro devem incluir a capacitação (art. 22, V, parágrafo único, I PNAS-2012)26.

A questão referente à gestão do trabalho, à capacitação e à educação permanente é responsabilidade de todos os entes da federação (art. 12, art. 15, XXI - PNAS/2012) ${ }^{25}$, compreendida como ação de valorização do trabalhador e desprecarização da relação e das condições de trabalho (art. 109 PNAS -2012) ${ }^{\mathbf{2 6}}$.

Educação permanente, como definido por Ferreira $^{22}$, significa o atendimento às necessidades de formação e qualificação sistemática e continuada dos trabalhadores do Suas. É um processo contínuo de construção de conhecimento, tendo por objetivo melhorar e ampliar a capacidade laboral dos trabalhadores, em função de suas necessidades individuais, da equipe de trabalho e da respectiva instituição, das necessidades dos usuários e da demanda social.

Prevê o plano municipal de assistência social 2014/2017, entre seus objetivos específicos, a implementação do Plano Municipal de Educação Permanente, em consonância com a Política Nacional de Educação Permanente do Suas, garantindo qualificação continuada aos profissionais da assistência social, fomentando a produção de conhecimento, a sistematização do trabalho desenvolvido e a publicização deles, por meio do Centro de Capacitação da Política de Assistência Social.

Previsão que é repetida no plano municipal 2018-2021, ressaltando as diretrizes da
NOB-RH/Suas 21. Educação e capacitação profissional obrigatória e permanente refletem diretamente o nível de valorização do usuário da política socioassistencial e do profissional que atua nas diferentes frentes da assistência social.

Questionados os participantes da entrevista, não houve uniformidade nas respostas sobre a capacitação para atuação nos Cras básico e especial. Dos entrevistados, alguns afirmaram que receberam capacitação para atuar no Cras e Creas, e recebem capacitação permanente. Outros não receberam nem recebem capacitação para o exercício de suas funções.

Esse cenário permite concluir que há, eventualmente, oferta de cursos, mas não são obrigatórios, tampouco observam um planejamento para atuação dos profissionais. Segundo um entrevistado "Há previsão de capacitação permanente. Não é obrigatório" (Ecras); e outro entrevistado completou, "A última que teve no Cras foi sobre identificação civil” (Ecras).

\section{Instalações, Centro de Referência de Assistência Social (Cras), Campo Grande, município do Rio de Janeiro}

As unidades destinadas à execução das ações de proteção social, entre elas, a segurança de acolhida, devem conter, conforme estabelecido na NOB-SUAS ${ }^{21,22}\left(\operatorname{art.4}{ }^{\circ}, I\right)$, condições de recepção, escuta profissional qualificada, informação, referência, concessão de benefícios, aquisições materiais, sociais e socioeducativas.

Evidentemente, esses espaços devem observar todos os princípios contidos na Convenção Internacional sobre os Direitos das Pessoas com Deficiência ${ }^{1}$ e na $\mathrm{LBI}^{2}$, nas quais a acessibilidade é um princípio básico, essencial e fundamental. Não é possível tratar de inclusão sem garantir acessibilidade.

Em um dos prédios visitados, o atendimento é feito no $2^{\circ}$ andar, cujo acesso é feito por uma escada estreita. Não apenas pessoas com deficiência têm dificuldade de acesso ao $2^{\circ}$ pavimento, local onde acontecem os atendimentos, mas grávidas, idosos e crianças. A diretora esclareceu, demonstrando preocupação, 
que, quando necessário, "as técnicas descem e fazem o atendimento no andar de baixo" (Ecras). Nesse Cras, verificamos que estão sendo construídos cubículos no andar térreo para atendimento ao público, obra que, no momento da visita, estava parada.

Em todos, as instalações são bastante precárias, em muitos, não há sequer privacidade para os atendimentos ou o número de salas para o atendimento individual é insuficiente. Em um dos equipamentos, não há sequer mesas, cadeiras e computadores suficientes para todos os profissionais que precisam se revezar na utilização, como se teve a oportunidade de presenciar. Chamou atenção que nenhuma das unidades tem estrutura física capaz de assegurar o sentimento de acolhimento, segurança e conforto essencial à proteção social.

Os espaços onde estão instalados os Cras e o Creas reproduzem a pobreza, a carência e a exposição em que esses grupos se encontram, e revelam persistir o estigma da caridade nas ações e serviços ofertados, prevalecendo a improvisação à profissionalização na realização da política socioassistencial.

Couto et al. ${ }^{24}$, em trabalho conjunto sobre a implantação do Suas em São Paulo e em Minas Gerais, alertam que o Cras não é simplesmente uma sigla emblemática, mas carrega sentidos e revela intencionalidades de um novo desenho institucional da assistência social. E prosseguem:

O CRAS não pode ser compreendido simplesmente como uma edificação. A disposição dos espaços e sua organização refletem a concepção sobre o trabalho social com famílias adotada pelo município ${ }^{24(2689)}$.

\section{Informação e intersetorialidade, Centro de Referência de Assistência Social (Cras), Campo Grande, Muni- cípio do Rio de Janeiro}

Os serviços do $\mathrm{Suas}^{\mathbf{3}}$ e do Sus ${ }^{\mathbf{7}}$ deverão promover ações articuladas para garantir à pessoa com deficiência e sua família a aquisição de informações, orientações e formas de acesso às políticas públicas disponíveis, com a finalidade de propiciar sua plena participação social (o art. 17 da LBI) ${ }^{2}$.

Como maciçamente respondido pelos participantes dos centros de referência, a demanda que chega ao Cras e ao Creas, chega espontaneamente, em regra, em busca do benefício do Bolsa Família e do BPC, momento que a pessoa é incluída no cadastro único do Governo Federal.

Nos Cras, não há programa, projeto ou serviço destinado à pessoa com deficiência mental, além do BPC, sendo as informações disponibilizadas em ações sociais, cartazes, com os líderes comunitários e nas escolas.

No Creas, os participantes apontaram que as informações e orientações acerca das políticas disponíveis às pessoas com deficiência mental com a finalidade de propiciar sua plena participação social são divulgadas nos atendimentos individuais e coletivos, e em ações sociais na comunidade. Contudo, afirmaram inexistir, a nível de Creas, políticas específicas para pessoa com deficiência mental.

Todos os entrevistados, curadores e curatelados, manifestaram interesse e necessidade de receber informações sobre a existência de projetos, programas e serviços voltados à pessoa com deficiência relacionados com a saúde, a educação, o lazer e os esportes. Os poucos curatelados que compreenderam as perguntas, igualmente, expressaram sua necessidade, especialmente em relação ao lazer, e demonstraram uma imensa vontade de trabalhar.

O desconhecimento da $\mathrm{LBI}^{2}$, seus direitos e garantias foi unânime; disse um dos curadores: "mas gostaria de conhecer". Igualmente, não participam de programas voltados à convivência familiar e comunitária, envolvendo a pessoa com deficiência; afirmou outro curador que "não existe programa ou projeto comunitário próximo".

Os entrevistados não participam de programas ou projetos destinados à habilitação, reabilitação, ao desenvolvimento da autonomia da pessoa com 
deficiência sob sua responsabilidade "porque não conhece", "porque nunca foi oferecido", "porque não sabe como fazer", "porque não sabe a quem recorrer" (falas de curadores).

A ausência de ações que garantam a divulgação de informações sobre serviços, programas, projetos e benefícios tendo como destinatários à pessoa com deficiência mental pode ser explicada, além da incapacidade operacional das unidades, pela inexistência de oferta. Simplesmente, não há oferta a ser divulgada, além do benefício de renda mínima.

Chama atenção o fato de nenhum dos entrevistados (curadores e curatelados), todos com renda muito baixa, não participarem de qualquer programa ou serviço de acolhida, de habilitação, reabilitação, de convivência familiar e comunitária.

Os entrevistados dos Cras e Creas, questionados sobre a oferta de cuidador social e residência inclusiva para as pessoas com deficiência mental, responderam que não têm este serviço, ou o desconhecem, ou, simplesmente não responderam; outros, que "essa pergunta é para Subsecretaria da Pessoa com Deficiência”.

As famílias e pessoas em situação de vulnerabilidade social, em geral, necessitam ser incluídos em diversas políticas, saúde, educação, moradia, garantia de renda. Somente por meio da atuação conjunta e integrada dos diversos setores públicos poderão ser obtidos resultados efetivos.

\section{Serviços de proteção social básico e especial, Centro de Referência de Assistência Social (Cras), Campo Grande, município do Rio de Janeiro}

A Tipificação Nacional de Serviços Socioassistenciais, aprovada pela Resolução ${ }^{0}$ 10927, padronizou em todo o território nacional os serviços de proteção social básica e especial, estabelecendo o conteúdo essencial de cada um, o público usuário e os resultados esperados.

Estabelece os serviços que devem ser prestados nos Cras e no Creas e os que podem ser realizados mediante parceria das entidades com os órgãos gestores.
Foram selecionados alguns serviços expressamente previstos na $\mathrm{LBI}^{2}$ e na Tipificação Nacional de Serviços Socioassistenciais para verificar sua implantação em Campo Grande e execução por intermédio dos Cras e Creas.

\section{Residências inclusivas}

Entre os direitos da pessoa com deficiência, a $\mathrm{LBI}^{2}$ prevê o direito à moradia digna, que deverá ser ofertada no caso da pessoa com deficiência, com vínculos familiares rompidos ou fragilizados, na modalidade de residência inclusiva:

Art. 31. A pessoa com deficiência tem direito à moradia digna, no seio da família natural ou substituta, com seu cônjuge ou companheiro ou desacompanhada, ou em moradia para a vida independente da pessoa com deficiência, ou, ainda, em residência inclusiva.

§ 10 O poder público adotará programas e ações estratégicas para apoiar a criação e a manutenção de moradia para a vida independente da pessoa com deficiência.

§ 20 A proteção integral na modalidade de residência inclusiva será prestada no âmbito do SUAS à pessoa com deficiência em situação de dependência que não disponha de condições de autossustentabilidade, com vínculos familiares fragilizados ou rompidos. [Grifo nosso].

Em 2014, foram publicadas, pelo Ministério do Desenvolvimento Social, orientações sobre o serviço de acolhimento institucional para jovens e adultos com deficiência em residências inclusivas, ressaltando que a proposta se respalda em compromissos assumidos pelo Brasil na Organização das Nações Unidas (ONU) ao ratificar a Convenção Internacional de Direitos da Pessoas com Deficiência':

A Residência Inclusiva tem o propósito de romper com a prática do isolamento, de mudança do paradigma de estruturação de serviços de acolhimento para pessoas com deficiência em áreas afastadas ou que não favoreçam o convívio comunitário. 
Tem como finalidade propiciar a construção progressiva da autonomia e do protagonismo no desenvolvimento das atividades da vida diária, a participação social e comunitária e o fortalecimento dos vínculos familiares com vistas à reintegração e/ou convivência ${ }^{27}$.

\section{Cuidador social}

O cuidador social está previsto no art. $39 \$ 2^{\circ} \mathrm{da}$ $\mathrm{LBI}^{2}$. São profissionais de apoio para as pessoas com deficiência em situação de dependência. Devem estar disponíveis em todos os serviços socioassistenciais, e não apenas nos serviços de alta complexidade que envolvam acolhimento institucional. Nos Cras que ofertam o Serviço de Convivência e Fortalecimento de Vínculos (SCFV), deve haver esse profissional, e como verificamos, não há.

\section{Serviço de Convivência e Fortaleci- mento de Vínculos (SCFV)}

O SCFV deverá ser organizado por faixa etária. Entre os usuários, estão: crianças, jovens, adultos e idosos em situação de vulnerabilidade em consequência da deficiência. São diversos os objetivos; exemplificativamente, entre eles, para faixa de 30 anos a 59 anos, pode-se citar: complementar as ações da família e comunidade na proteção e no fortalecimento dos vínculos familiares e sociais,

[...], propiciar vivências para o alcance de autonomia e protagonismo social, estimulando a participação na vida pública no território, além de desenvolver competências para a compreensão crítica da realidade social e do mundo contemporâneo ${ }^{26}$.

Os Cras em Campo Grande ofertam o serviço à comunidade. Contudo, quanto à pessoa com deficiência mental,

Não há nenhum trabalho específico, dependendo da deficiência a pessoa pode participar.

É ofertado às diversas faixas etárias sem discriminação quanto ao fator saúde mental que são considerados público prioritário. [Eles são] integrados, [não] incluso. (Ecras).

\section{Habilitação, reabilitação e desenvol- vimento da autonomia}

A habilitação e a reabilitação são um dos objetivos a serem atingidos pela política de assistência social à pessoa com deficiência estabelecido na $\mathrm{LBI}^{2}$, $\mathrm{e}$ igualmente consta entre as seguranças definidas na Loas ${ }^{8}$ como objetivo da assistência social.

Nos Cras e Creas, não há serviço ou programa que preveja a inclusão da pessoa com deficiência mental, repetindo os participantes a afirmação que os serviços são abertos ao público.

Estar aberto ao público não significa inclusão da pessoa com deficiência, especialmente se a condição é de deficiência mental que vai exigir a utilização de ferramentas específicas. Dizer que todos podem participar não garante que a pessoa com deficiência mental participe, interaja ou adquira competências. Inclusão é criar as condições físicas, atitudinais e ambientais a participação da pessoa com deficiência com ganhos para todos os envolvidos, sejam eles com ou sem deficiência.

\section{Serviço de proteção social básica no domicílio}

É serviço fundamental para inclusão e atendimento das necessidades do indivíduo e sua família, prevenindo situações de confinamento e isolamento de pessoas com deficiência e idosos. O serviço prevê a elaboração de um plano de desenvolvimento do usuário.

Segundo a grande maioria dos entrevistados, após a LBI, não foram implantadas mudanças na oferta de serviços e programas, salvo a contratação de terceirizados com deficiência. Ressaltamos que, em alguns Cras, $100 \%$ dos entrevistados afirmaram desconhecer a LBI, e apenas um dos entrevistados, considerando Cras e Creas, afirmou ter recebido capacitação específica para trabalhar dentro dos novos paradigmas. 


\section{Considerações finais}

A Convenção Internacional de Direitos das Pessoas com Deficiência em vigor no Brasil com status de norma constitucional desde 2009, portanto, há dez anos, tem o propósito de promover, proteger e assegurar o exercício pleno e equitativo de todos os direitos humanos e liberdades fundamentais por todas as pessoas com deficiência e promover o respeito pela sua dignidade inerente.

Enfim, proporcionar às pessoas com deficiência uma nova dimensão de vida, seja no plano individual, seja no coletivo, representa um grande desafio para todas as nações que a ratificaram.

Essa Convenção ingressou no ordenamento jurídico nacional com status de norma constitucional, e foi posteriormente regulamentada pela LBI em 2015.

Contudo, os resultados colhidos na pesquisa de campo foram bastantes desalentadores. Permanece como uma ideia, ainda não é uma realidade para as pessoas com deficiência tampouco para as pessoas com deficiência mental.

$\mathrm{O}$ estudo desenvolvido teve por foco as atribuições conferidas pela LBI à assistência social, tendo esta sido erigida pela Constituição da República de 1988 como integrante do tripé da seguridade social.

Mostrou-se de relevada importância o estudo do Suas, pouco conhecido, contudo, com imensa responsabilidade atribuída pela LBI na concretização de direitos sociais, tendo como destinatários as pessoas com deficiência, especificamente, no nosso estudo, a pessoa com deficiência mental.

Sem o conhecimento aprofundado desse sistema, sua organização, estrutura e atribuições pouco pode caminhar na concretização dos direitos sociais que exigem ações afirmativas do Estado e participação da sociedade.

Sem conhecimento, não há demanda, prevalecendo o estado atual sem mudanças que elevem a pessoa com deficiência à condição de cidadão.

A ignorância da base normativa constitucional referente à assistência social e sua efetiva implantação permite que se prolongue a omissão do Estado na implantação de políticas públicas com corte social voltado à pessoa com deficiência mental e no cumprimento de compromissos internacionais de relevada importância, capaz de projetar o Brasil a melhor nível de desenvolvimento humano.

A pesquisa de campo revelou que não foram promovidas ações para implantação de programas, serviços e projetos previstos na LBI voltados à pessoa com deficiência mental, limitando-se os equipamentos dos Cras e Creas à alimentação e à atualização do cadastro único do governo federal para obtenção do BPC pelas famílias que preenchem os requisitos legais.

Os titulares dos direitos garantidos previstos na LBI e na Convenção Internacional de Direitos da Pessoas com Deficiência continuam a desconhecê-los.

Ao Suas, ao lado do SUS, foram atribuídas competências e obrigações fundamentais para o atendimento das necessidades do cidadão em estado de vulnerabilidade e risco social, permanecendo, após 30 anos de sua instituição como direito social e mais de 10 anos como um sistema nacional, completamente desconhecido da sociedade.

Acrescentem-se a esse resultado os dados colhidos com os participantes da pesquisa de campo, potenciais usuários dos serviços do Suas (curadores e curatelados) que, igualmente, expressaram desconhecê-lo. Embora uns poucos tenham afirmado ter ouvido falar do Cras, pode-se concluir o diminuto alcance das ações da assistência social em relação às pessoas com deficiência mental cujas informações, como verificamos nas entrevistas, são fornecidas precipuamente nos atendimentos feitos pela saúde.

Infelizmente, o cenário é alarmante: essas pessoas estão reclusas em seus ambientes domésticos; à exceção do BPC, não participam de qualquer programa, serviço ou projeto, nos moldes previstos na Convenção Internacional de Direitos da Pessoas com Deficiência e na LBI.

À toda evidência, a política de assistência social é muito mais ampla que um programa de garantia de renda mínima. Um programa de 
renda mínima nos moldes do BPC é incapaz de concretizar a garantia de proteção social, da erradicação da pobreza, enfim, de promover o bem de todos.

$\mathrm{O}$ art. $3^{\circ}$ da Constituição da República estabelece como objetivos fundamentais da República Federativa do Brasil: I - construir uma sociedade livre, justa e solidária; II - garantir o desenvolvimento nacional; III - erradicar a pobreza e a marginalização e reduzir as desigualdades sociais e regionais; IV - promover o bem de todos, sem preconceitos de origem, raça, sexo, cor, idade e quaisquer outras formas de discriminação.

A omissão do Estado Brasileiro na efetivação dos compromissos assumidos ao ratificar Convenção de Direitos da Pessoa com Deficiência foi registrada no relatório de setembro de 2015 da Organização das Nações Unidas, em cumprimento ao disposto no art. 35 e art. 36 da Convenção Internacional de Direitos da Pessoas com Deficiência, do qual destacamos algumas das recomendações $1:$ 20. O Comitê está preocupado com a falta de estratégias para promover especificamente o conteúdo da Convenção e o modelo de direitos humanos da deficiência para o público em geral, funcionários públicos e atores privados; 21. Comitê recomenda que o Estado Parte ofereça treinamento sobre os direitos reconhecidos pela Convenção a todas as autoridades públicas e funcionários do setor público e privado que trabalhem com pessoas com deficiência. O Comitê recomenda ainda que sejam fornecidas informações sobre a Convenção para pessoas com deficiência; 23. O Comitê recomenda que o Estado Parte tome medidas eficazes para garantir a acessibilidade do ambiente construído, transportes, informação e comunicação e dos serviços abertos ao público; e 36. O Comitê está preocupado com a falta de acesso a serviços de apoio e subsídios, em especial os serviços de assistência pessoal, que visam possibilitar às pessoas com deficiência viver de maneira independente e serem incluídas na comunidade. O Comitê também está preocupado que o Estado Parte não tenha uma estratégia global para substituir a institucionalização pela vida fundamentada na comunidade para pessoas com deficiência.

A despeito de avanços relevantes nas garantias normativas de direitos sociais, inclusive com direitos e garantias constitucionais nesse sentido, a pesquisa apresentada mostrou que esse reconhecimento legislativo não foi capaz de reduzir efetivamente as desigualdades sociais. Evidentemente que o desafio permanente é o poder público conferir à política de assistência social os destaques político e orçamentário necessários ao seu fortalecimento.

\section{Agradecimentos}

Gostaríamos de agradecer a todos participantes que propiciaram esta pesquisa.

\section{Colaboradores}

Abreu TPC (0000-0001-6510-4159)* contribuiu com a pesquisa de campo; pesquisa documental; e redação. Vilardo MAT (00000002-6632-2622)* contribuiu com a revisão crítica do conteúdo e aprovação da versão final do manuscrito. Ferreira AP (0000-00027122-5042)* contribuiu para a concepção, o planejamento, a análise e a interpretação dos dados; revisão crítica do conteúdo; e aprovação da versão final do manuscrito. 


\section{Referências}

1. Brasil. Decreto ${ }^{\circ}$ 6.949, de 25 de agosto de 2009. Promulga a Convenção Internacional sobre os Direitos das Pessoas com Deficiência e seu Protocolo Facultativo, assinados em Nova York, em 30 de março de 2007 [internet]. Diário Oficial da União. 26 Ago 2009. [acesso em 2018 set 15]. Disponível em: http://www. planalto.gov.br/ccivil_03/_ato2007-2010/2009/decreto/d6949.htm.

2. Brasil. Lei $\mathrm{n}^{\circ}$ 13.146, de 06 de julho de 2015. Institui a Lei Brasileira de Inclusão da Pessoa com Deficiência (Estatuto da Pessoa com Deficiência) [internet]. Diário Oficial da União. 7 Jul 2015. [acesso em 2018 set 15]. Disponível em: http://www.planalto.gov.br/ ccivil_03/_Ato2015-2018/2015/Lei/L13146.htm.

3. Brasil. Secretaria Nacional de Assistência Social. Norma Operacional Básica NOB/SUAS: construindo as bases para a implantação do Sistema Único de Assistência Social [internet]. Brasília, DF: Secretaria Nacional de Assistência Social; 2009. [acesso em 2017 out 19]. Disponível em: https://www.mds.gov.br/webarquivos/publicacao/assistencia_social/Cadernos/ Consolidacao_Suas.pdf.

4. Nusbaumm M. Fronteiras da justiça: deficiência, nacionalidade, pertencimento à espécie. São Paulo: Martins Fontes; 2013.

5. Declaração Universal dos Direitos Humanos. Assembleia Geral das Nações Unidas em Paris [internet]. Paris: Assembleia Geral das Nações Unidas; 1948. [acesso em 2017 jun 15]. Disponível em: https://www. unidosparaosdireitoshumanos.com.pt/what-are-human-rights/universal-declaration-of-human-rights/ articles-01-10.html.

6. Brasil. Constituição da República Federativa do Brasil [internet]. Brasília, DF: Senado Federal; 1988. [acesso em 2018 set 15]. Disponível em: http://www.planalto.gov.br/ccivil_03/Constituicao/Constituiçao.htm.

7. Brasil. Lei $n^{\circ} 8.080$, de 19 de setembro de 1990. Dispõe sobre as condições para a promoção, proteção e recuperação da saúde, a organização e o funciona- mento dos serviços correspondentes e dá outras providências [internet]. Diário Oficial da União. 20 Set 1990. [acesso em: 2019 jan 10]. Disponível em: http:// www.planalto.gov.br/ccivil_03/leis/L8080.htm.

8. Brasil. Lei no ${ }^{\circ}$ 8.742, de 7 de dezembro de 1993. Dispõe sobre a organização da Assistência Social e dá outras providências [internet]. Diário Oficial da União. 8 Dez 1993. [acesso 2017 mar 13]. Disponível em: http:// www.planalto.gov.br/ccivil_03/LEIS/L8742compilado.htm.

9. Lopes LVCF. Convenção sobre os Direitos das Pessoas com Deficiência da ONU, seu Protocolo Facultativo e a Acessibilidade [dissertação]. São Paulo: PUC/ SP; 2009.

10. Brasil. Decreto n ${ }^{\circ} 5.296$ de 2 de dezembro de 2004 . Regulamenta as Leis $\mathrm{n}^{\circ} 10.048$, de 8 de novembro de 2000, que dá prioridade de atendimento às pessoas que especifica, e ${ }^{0} 10.098$, de 19 de dezembro de 2000, que estabelece normas gerais e critérios básicos para a promoção da acessibilidade das pessoas portadoras de deficiência ou com mobilidade reduzida, e dá outras providências [internet]. Diário Oficial da União. 3 Dez 2004. [acesso em 2018 set 15]. Disponível em: http://www.planalto.gov.br/ccivil_03/Ato2004-2006/2004/Decreto/D5296.htm.

11. Organização Mundial de Saúde. Organização Pan-Americana da Saúde. Declaração de Montreal sobre a Deficiência Intelectual Montreal [internet]. Montreal: OPS/OMS; 2004 [acesso em 2018 nov 23]. Disponível em: http://www.educadores.diaadia.pr.gov. br/arquivos/File/pdf/declaracao_montreal.pdf.

12. Feminella AP, Lopes LF. Lei Brasileira de Inclusão da Pessoa com Deficiência - Comentada. In: Setubal JM, Fayan RAC, organizadores. Campinas: Fundação FEAC; 2016.

13. Brasil. Lei ${ }^{\circ}{ }^{10.216}$, de 6 de abril de 2001. Dispõe sobre a proteção e os direitos das pessoas portadoras de transtornos mentais e redireciona o modelo assistencial em saúde mental [internet]. Diário Oficial 
da União. 7 Abr 2001. [acesso em 2018 nov 23]. Disponível em: https://hpm.org.br/wp-content/uploads/2014/09/lei-no-10.216-de-6-de-abril-de-2001.pdf.

14. Alencar AG, Redondo L, Ortiz B. Transtornos mentais e a deficiência psicossocial [internet]. Programa de Esquizofrenia da Escola Paulista de Medicina (PROESQ-UNIFESP). 7 Ago 2017. [acesso em: 2018 jun 18]. Disponível em: http://www.sinicesp.org.br/ inclusao/noticias/2017_038.htm.

15. Organização Mundial da Saúde. CIF: Classificação Internacional de Funcionalidade, Incapacidade e Saúde. São Paulo: Editora da Universidade de São Paulo - EDUSP; 2003.

16. Costa AMM. O Reconhecimento da Pessoa com Transtorno Mental Severo como Pessoa com deficiência: Uma Questão de Justiça [internet]. [local desconhecido]: Inclusive - Inclusão e Cidadania; 2011. [acesso em 2018 jul 19]. Disponível em: https://www.inclusive.org.br/wp-content/uploads/O_reconhecimento.pdf.

17. Brasil. Decreto $n^{0}$ 6.214, de 26 de setembro de 2007 . Regulamenta o benefício de prestação continuada da assistência social devido à pessoa com deficiência e ao idoso de que trata a Lei $\mathrm{n}^{\circ} 8.742$, de 7 de dezembro de 1993 , e a Lei $n^{\circ} 10.741$, de $1^{\circ}$ de outubro de 2003, acresce parágrafo ao art. 162 do Decreto no 3.048, de 6 de maio de 1999, e dá outras providências [internet]. Diário Oficial da União. 27 Set 2007. [acesso em 2018 jul 19]. Disponível em: http://www. planalto.gov.br/ccivil_03/_Ato2007-2010/2007/Decreto/D6214.htm.

18. Brasil. Portaria Conjunta MDS/INSS no 2 de 30.03.2015. Dispõe sobre critérios, procedimentos e instrumentos para a avaliação social e médica da pessoa com deficiência para acesso ao Benefício de Prestação Continuada [internet]. Diário Oficial da União. 31 Mar 2015. [acesso em 2018 set 9]. Disponível em: http://www.normaslegais.com.br/legislacao/Portaria-conjunta-mds-inss-2-2015.htm.

19. Rosenvald N. Aplicação no Brasil da Convenção sobre os Direitos da Pessoa com Deficiência. IDIBE.
2016; 4(3):123-143.

20. Brasil. Plano Nacional de Assistência Social (PNAS) [internet]. Brasília (DF): Ministério do Desenvolvimento Social e Combate à Fome; 2009. [acesso em 2018 set 9]. Disponível em: http://www.mds.gov.br/ webarquivos/publicacao/assistencia_social/Normativas/PNAS2004.pdf.

21. Brasil. Ministério do Desenvolvimento Social e Combate à Fome. Norma Operacional Básica do Sistema Único de Assistência Social NOB/SUAS. Brasília, DF: Ministério do Desenvolvimento Social e Combate à Fome; 2005.

22. Ferreira SS. NOB-RH: Anotada e Comentada, 2011 [internet]. Brasília, DF: Ministério do Desenvolvimento Social e Combate à Fome; 2011. [acesso em 2018 set 12]. Disponível em: https://www.mds.gov. br/webarquivos/publicacao/assistencia_social/Normativas/NOB-RH_SUAS_Anotada_Comentada.pdf.

23. Brasil. Resolução n ${ }^{\circ} 33$, de 12 de dezembro de 2012. Aprova a Norma Operacional Básica do Sistema Único de Assistência Social -NOB/SUAS [internet]. Diário Oficial da União. 13 Dez 2012 [acesso em 2018 set 23]. Disponível em: file://C:/Users/aldoferreira/ Downloads/CNAS\%202012\%20-\%20033\%20-\%20 12.12.2012.pdf.

24. Couto BR, Yazbek MC, Silva MOS, et al. O Sistema único de Assistência Social no Brasil - uma realidade em movimento. São Paulo: Cortez; 2013.

25. Santos R, Brun AB. A política de assistência social no Brasil e os sistemas de proteções do sistema único de assistência social (SUAS). Jusbrasil.com.br. 2018. [acesso em 2018 set 15]. Disponível em: https://regilainesantos.jusbrasil.com. br/artigos/323125229/a-politica-de-assistencia-social-103no-brasil-e-os-sistemas-de-protecoes-do-sistema-unico-de-assistencia-social-suas.

26. Brasil. Decreto ${ }^{\circ} 7.788$, de 15 de agosto de 2012. Regulamenta o Fundo Nacional de Assistência Social, instituído pela Lei $\mathrm{n}^{\circ} 8.742$, de 7 de dezembro de 1993 , e dá outras providências [internet]. Diário Oficial da 
União. 16 Ago 2012 [acesso em 2018 jan 15]. Disponível em: http://www.planalto.gov.br/ccivil_03/_Ato20112014/2012/Decreto/D7788.htm.

27. Brasil. Resolução $n^{0}$ 34, de 28 de novembro de 2011. Define a Habilitação e Reabilitação da pessoa com deficiência e a promoção de sua integração à vida comunitária no campo da assistência social e estabele- ce seus requisitos [internet]. Diário Oficial da União. 29 Nov 2011 [acesso em 2018 set 18]. Disponível em: http://www.mds.gov.br/cnas/legislacao/resolucoes/ arquivos-2011/cnas-2011-034-28-11-2011.pdf.

Recebido em 14/08/2019

Aprovado em 15/10/2019

Conflito de interesses: inexistente

Suporte financeiro: não houve 